Tohoku J. Exp. Med., 2007, 213, 341-349

\title{
Bone Marrow-Derived Cells Mobilized by Granulocyte-Colony Stimulating Factor Facilitate Vascular Regeneration in Mouse Kidney after Ischemia/Reperfusion Injury
}

\author{
Susumu Akihama, ${ }^{1}$ Kazunari Sato, ${ }^{2}$ Shigeru Satoh, ${ }^{1}$ Norihiko Tsuchiya, ${ }^{1}$ \\ Tetsuro Kato, ${ }^{3}$ Atsushi Komatsuda, ${ }^{4}$ Makoto Hirokawa, ${ }^{4}$ Kenichi Sawada, ${ }^{4}$ \\ Hiroshi NANJO ${ }^{5}$ and TOMONORI HaBUCHI ${ }^{1}$ \\ ${ }^{1}$ Department of Urology, Akita University School of Medicine, Akita, Japan \\ ${ }^{2}$ Hiraka General Hospital, Yokote, Japan \\ ${ }^{3}$ Akita Prefectural Health Care Center, Akita, Japan \\ ${ }^{4}$ Department of Internal Medicine, Akita University School of Medicine, Akita, Japan \\ ${ }^{5}$ Department of Pathology, Akita University School of Medicine, Akita, Japan
}

Akimama, S., Sato, K., Satoh, S., Tsuchiya, N., Kato, T., Komatsuda, A., Hirokawa, M., Sawada, K., Nanjo, H. and Habuchi, T. Bone Marrow-Derived Cells Mobilized by Granulocyte-Colony Stimulating Factor Facilitate Vascular Regeneration in Mouse Kidney after Ischemia/Reperfusion Injury. Tohoku J. Exp. Med., 2007, 213 (4), 341-349 - Bone marrow-derived cells (BMDC) play crucial roles in tissue regeneration. Granulocyte-colony stimulating factor (G-CSF) mobilizes BMDC and may facilitate the repair of kidney tissues after ischemia/reperfusion (I/R) injury. The tissue protective action of resveratrol, an antioxidant, might modify the regenerating potential of BMDC in I/R renal injury. This study examined whether G-CSF and/or resveratrol affect the recruitment of BMDC into vascular endothelial cells and renal tubular cells and the kidney function after $\mathrm{I} / \mathrm{R}$ injury. I/R renal injury was induced in female mice that had been lethally irradiated and transplanted with male bone marrow cells. The mice were given saline, resveratrol or G-CSF, daily for 7 days. Non-irradiated and non-bone-marrow-transplanted female mice, which underwent the same kidney injury, were included as control. White blood cell (WBC) count and serum creatinine were monitored. Immunohistologic evaluation for renal tubular cells (cytokeratin) and endothelial cells (factor VIII-related antigen), and fluorescence in situ hybridization for mouse Y chromosome were performed. Although WBC was significantly higher in the G-CSF group, there was no significant difference in creatinine levels among all groups. Factor VIII-related antigen-positive cells with a Y-chromosome signal were identified in the capillary wall between renal tubuli and most frequently seen in the G-CSF group $(p<0.0001)$. Resveratrol did not affect kidney recovery in this model. No cytokeratin-positive renal tubular cells having a Y-chromosome signal were identified. In conclusion, BMDC are recruited into endothelial cell in I/R renal injury without apparent renal tubular cell regeneration, and G-CSF facilitates the endothelial cell regeneration. - Granulocyte-colony stimulating factor; resveratrol; bone-marrowderived cell; regeneration; ischemia/reperfusion injury

(C) 2007 Tohoku University Medical Press

Received June 26, 2007; revision accepted for publication November 6, 2007.

Correspondence: Prof. Tomonori Habuchi, Department of Urology, Akita University School of Medicine, 1-1-1 Hondo, Akita 010-8543, Japan.

e-mail: thabuchi@doc.med.akita-u.ac.jp 
Current stem cell research has demonstrated that bone marrow contains stem cells of a variety of organs, including hematopoietic and nonhematopoietic stem cells, such as mesenchymal stem cells, multipotent adult progenitor cells and endothelial precursor cells, and that these stem cells play a crucial role in tissue regeneration when they are recruited to target organs (Körbling and Estrov 2003).

Cytokines including granulocyte monocytecolony stimulating factor and granulocyte-colony stimulating factor (G-CSF) mobilize not only hematopoietic stem cells but also non-hematopoietic stem cells from bone marrow into the peripheral circulation (Takahashi et al. 1999). Orlic et al. (2001) demonstrated that bone-marrowderived cells (BMDC) mobilized by G-CSF into an ischemic heart facilitated the repair of the infarcted heart and improved the heart function. It has also been reported that BMDC mobilized by G-CSF accelerate the improvement of renal function and prevent renal tubular injury induced by cisplatin (Iwasaki et al. 2005). These findings indicate the therapeutic potential of G-CSF by recruiting BMDC to damaged tissues, although conflicting results that showed adverse effects of G-CSF on renal function were also reported (Tögel et al. 2004; Nishida and Hamaoka 2006).

The mechanisms of acute renal failure by ischemia/reperfusion (I/R) injury are being elucidated. It was reported that the response of kidneys damaged by I/R injury was dominated by tubular epithelial destruction and regeneration (Lin et al. 2003); however, recent studies have demonstrated that endothelial injury preceded renal tubular injury and was the primary cause of kidney dysfunction in acute renal failure by $\mathrm{I} / \mathrm{R}$ injury (Kakoki et al. 2000; Brodsky et al. 2002). Furthermore, reactive oxygen species are considered important factors in the pathophysiology of this type of kidney injury (Lameire and Vanholder 2004; Masztalerz et al. 2006).

These findings raise the question of whether BMDC mobilized by G-CSF to the kidney transform into endothelial cells and/or renal tubular cells and facilitate the recovery of renal function in $\mathrm{I} / \mathrm{R}$ injury. On the other hand, we previously demonstrated that resveratrol, an antioxidant, had a protective effect on kidney function after I/R injury by attenuating CD86 expression (Saito et al. 2005). The tissue protective action of resveratrol might modify the regenerating potential of BMDC. The aim of the present study was to elucidate whether G-CSF and/or resveratrol affect the recruitment of BMDC into vascular endothelial cells and tubular cells of the kidney and the recovery of kidney function after acute ischemic injury.

\section{Materials ANd Methods}

\section{Bone marrow transplantation}

Five- to six-week-old female recipient mice (BALB/c, CLEA Japan Inc., Tokyo) underwent wholebody X-ray irradiation of 10 Gray in a single dose to ablate their bone marrow. Meanwhile, the same number of male donor mice (BALB/c) was sacrificed by $\mathrm{CO}_{2}$ inhalation, and bone marrow cells of these mice were extracted from the femuri, suspended in RPMI-1640 medium (Gibco BRL, Tokyo), filtrated with a pore size of 40 $\mu \mathrm{m}$ (40 $\mu \mathrm{m}$ Cell Strainer, BD Biosciences, San Jose, CA, USA) and re-suspended in RPMI-1640 medium at a concentration of $3.0 \times 10^{7} / \mathrm{ml}$. After irradiation, female mice received an injection of male mouse bone marrow of $10^{7}$ cells through the tail vein.

\section{Ischemia/reperfusion renal injury}

After 4 weeks, 35 irradiated and bone marrowtransplanted female mice were randomly assigned either to the BMT/C group (9 mice), resveratrol group (13 mice) or G-CSF group (13 mice), and were anesthetized by intraperitoneal pentobarbital injection, and the right kidney of each mouse was removed. Since it has been reported that $30 \mathrm{~min}$ of bilateral I/R cause reversible renal ischemic injury without severe lethargy (Kale et al. 2003), we blocked left renal blood flow for 30 min with a vessel clamp (Disposable Clip, Natume Seisakusyo Co., Ltd., Tokyo) and then blood flow was restored. Eight non-irradiated and non-bone-marrow-transplanted female mice $(B A L B / c)$ underwent the same surgery.

\section{Drug administration}

Of 43 female mice that received the surgery, 39 $(90.7 \%)$ survived. Of the 39 mice, 8 in the control group and 8 in the BMT/C group were given normal saline $(0.2$ $\mathrm{ml}$, i.p.), 11 were given resveratrol (4 $\mathrm{mg} / \mathrm{kg}$ prepared in 
$10 \%$ ethanol, i.p.) (Sigma, St. Louis, MO, USA) and 12 G-CSF (100 $\mu \mathrm{g} / \mathrm{kg}$, s.c.) (recombinant human G-CSF, Chugai Pharmaceutical Co. Ltd., Tokyo) from day 1 daily for 7 consecutive days.

\section{Blood and tissue samples}

Peripheral blood samples were collected from the tail vein, and white blood cells (WBC) were counted on a Burker-Turk glass slide, and serum creatinine levels were measured by Jaffe's method using a Kyokuto creatinine test (Kyokuto Pharmaceutical Industrial Co., Ltd., Tokyo) according to the manufacturer's instructions. WBC and serum creatinine levels were monitored on day 0 (preoperatively), 1, 3 and 7 and weekly thereafter for 4 weeks. All mice were then sacrificed, and the kidneys were removed and fixed in $10 \%$ buffered formalin for 24 hrs, embedded in paraffin, and used for histological studies.

\section{Immunohistochemistry}

Five- $\mu \mathrm{m}$ sections were sliced from each paraffinembedded tissue block and mounted on glass slides. Tissue sections were deparaffinized, dehydrated, digested in $0.4 \%$ pepsin for $40 \mathrm{~min}$ at $37^{\circ} \mathrm{C}$, and rinsed in water. Endogenous peroxidase activity was blocked by incubation in $0.3 \% \mathrm{H}_{2} \mathrm{O}_{2} /$ methanol for $20 \mathrm{~min}$ at room temperature, and the tissue sections were rinsed in PBS. A protein blocking agent (Dako Japan Co. Ltd., Tokyo) was applied for $30 \mathrm{~min}$, and the tissue sections were rinsed in PBS.

For demonstration of the factor-VIII related antigen, the primary antibody (rabbit polyclonal anti-factor-VIIIrelated antigen antibody, Dako Japan Co., Ltd.) was applied on the sections at a dilution of 1/100 for $60 \mathrm{~min}-$ utes at room temperature. To detect the antigen-antibody reaction, a LSAB2 Biotinylated Link Antibody Rabbit/ Mouse $^{\mathrm{TM}}$ kit (Dako Japan Co., Ltd.) was used according to the manufacturer's instructions.

For the demonstration of cytokeratin 18 , the primary antibody (CBL 177, Cymbus-Biotechnology Ltd., Hampshire, UK) was applied on sections at a dilution of $1 / 300$ overnight at $4^{\circ} \mathrm{C}$. To detect the antigen-antibody reaction, a ChemMate EnVision Detection Kit/HRP (DAB) Rabbit/Mouse ${ }^{\mathrm{TM}}$ kit (Dako Japan Co., Ltd.) was used according to the manufacturer's instructions.

\section{Fluorescence in situ hybridization}

A DNA probe for total mouse chromosome Y (Q-Biogene Inc., Carlsbad, CA, USA) was diluted with 2 volumes of hybridization buffer (CEP hybridization buffer $^{\mathrm{TM}}$, Vysis Inc., Downers Grove, IL, USA), and an aliquot of the mixture was applied onto a tissue section, which was then covered with a cover slip and shielded with rubber cement. The probe mixture and target DNA were codenatured at $80^{\circ} \mathrm{C}$ for $2 \mathrm{~min}$, annealed at $50^{\circ} \mathrm{C}$ for $30 \mathrm{~min}$, and then incubated at $37^{\circ} \mathrm{C}$ overnight in a handsfree denaturation and hybridization system (HYBrite, Vysis Inc.). After hybridization, tissue sections were washed in a solution of $1.5 \mathrm{M}$ urea and $0.1 \mathrm{x}$ SCC (pH7.2) at $45^{\circ} \mathrm{C}$ for $10 \mathrm{~min}$, and this washing was repeated 3 times. Tissue sections were equilibrated in $2 \mathrm{x}$ SCC for 5 min at room temperature. Nuclei were then counterstained with 4,6-diamino-2-phenylindole p-phenylenediamine and anti-fade mounting solution (Vysis Inc.). The tissue sections were kept in a black box at $4^{\circ} \mathrm{C}$ until fluorescence microscopic evaluation.

Histological identification of tissue regeneration by bone-marrow-derived cells

To identify the possible regeneration of endothelial cells and tubular epithelial cells by BMDC within the mouse kidney, Y-chromosome in situ hybridization was combined with immunohistochemistry.

Microscopic images of the mouse kidney stained with an antibody for renal tubular cells (cytokeratin 18) or endothelial cells (factor-VIII-related antigen) were captured under a microscope (BX-50, Olympus Corp., Tokyo) equipped with a CCD camera (Nikon, Tokyo) with a magnification of $\times 200$. Fluorescence in situ hybridization with a DNA probe for mouse Y chromosome was then performed on the same slide. The slide was scanned with a magnification of $\times 400$, and an image of the area in which Y-chromosome-positive cells were most frequently observed was captured using a CCD camera (Nikon). Using immunohistochemistry pictures as a reference, the number of immunohistologically positive cells with a Y-chromosome signal was counted.

The results are represented as the mean \pm standard deviation. Statistical analyses were performed by Student's non-paired $t$-test using StatView 5.0 J software (SAS Institute Japan Ltd., Tokyo), and $p$-values less than 0.05 were considered significant.

This study was approved by the Institutional Ethical Board of the Akita University School of Medicine.

\section{Results}

\section{Mouse body weight}

Postoperatively, the mean body weight of 


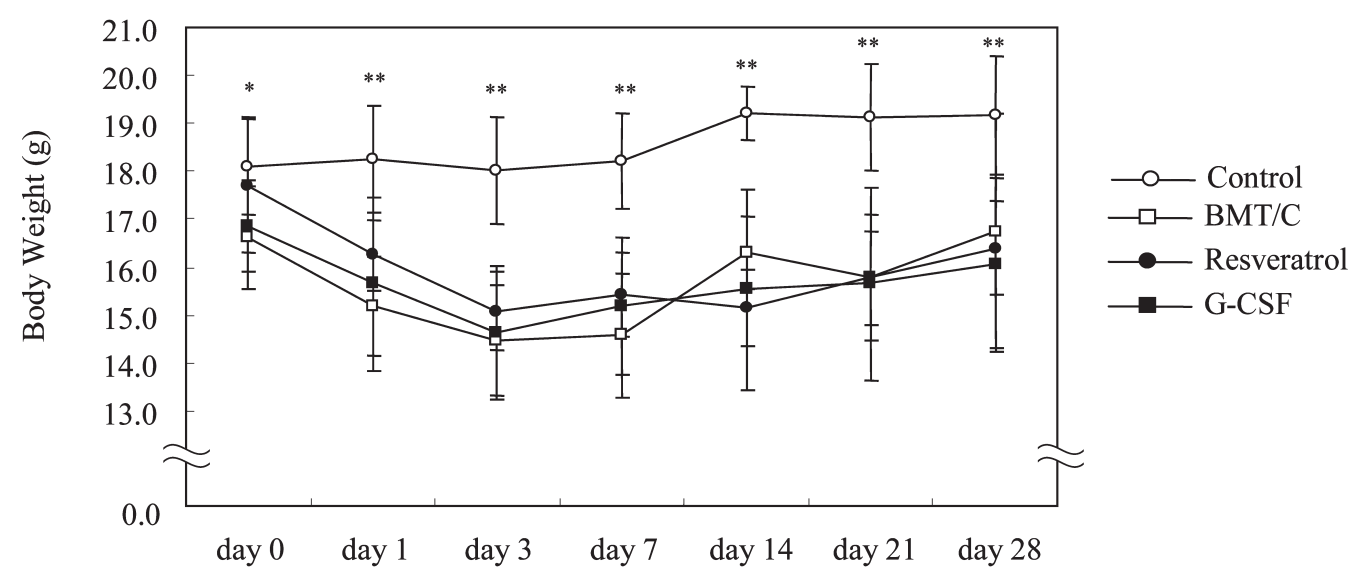

Fig. 1. Mouse body weights after induction of renal ischemia/reperfusion injury. Mean body weight of irradiated and bone-marrow-transplanted mice in BMT/C, G-CSF and resveratrol groups was lower than that of non-irradiated and non-bone-marrow-transplanted control mice, but there were no significant differences in mean body weight among BMT/C, G-CSF and resveratrol groups. BMT/C, irradiated and bone-marrow-transplanted control.

$* p<0.05, * * p<0.0001$; Control vs BMT/C.

irradiated mice in the BMT/C, G-CSF and resveratrol groups continuously decreased until day 3 and gradually increased thereafter, while the mean body weight of the non-irradiated control mice did not show any apparent decrease. The mean body weights of the irradiated mice in BMT/C, $\mathrm{G}-\mathrm{CSF}$ and resveratrol groups were lower than that of non-irradiated control mice from day 1 until day 28 , but there was no significant difference in the mean body weight among BMT/C, G-CSF and resveratrol groups at any time of monitoring (Fig. 1).

\section{White blood cell count}

WBC was significantly higher in the G-CSF group at mean levels of $27.7 \times 10^{3} \pm 10.3 \times 10^{3} / \mu 1$ and $32.8 \times 10^{3} \pm 14.6 \times 10^{3} / \mu 1$ on day 3 and day 7 , respectively, while there was no significant difference in the mean $\mathrm{WBC}$ among the BMT/C, resveratrol and non-irradiated control groups at any time of monitoring (Fig. 2).

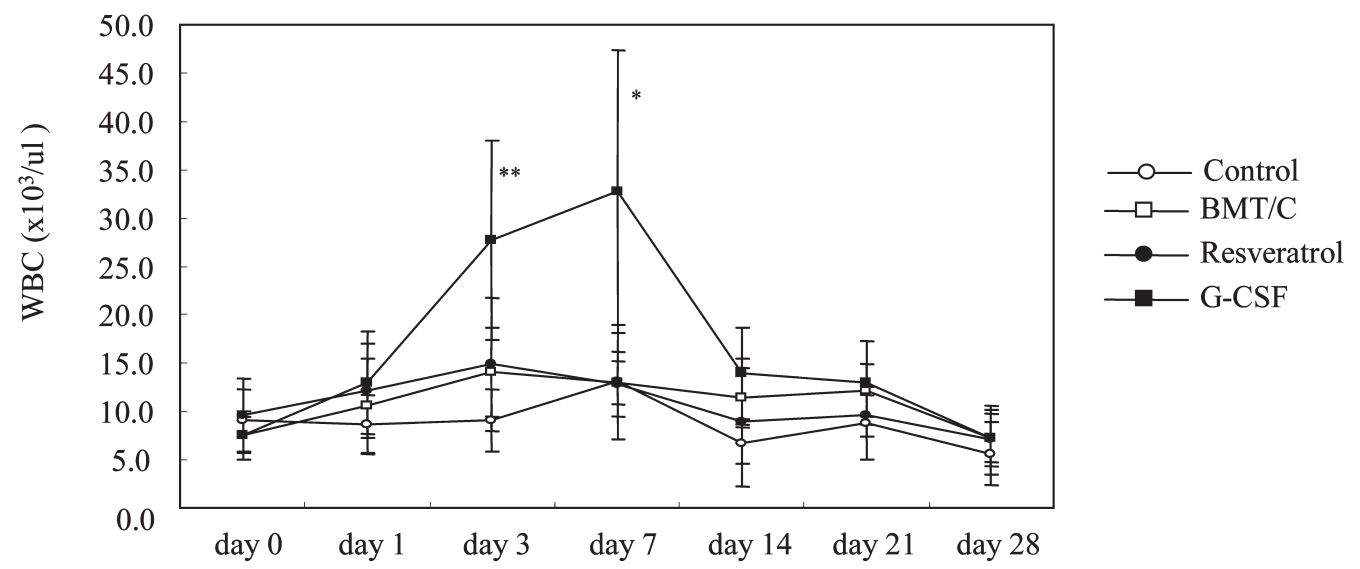

Fig. 2. White blood cell counts after induction of renal ischemia/reperfusion injury. White blood cell count was significantly higher in the G-CSF group on day 3 and day 7. WBC, white blood cell; $\mathrm{BMT} / \mathrm{C}$, irradiated and bone-marrow-transplanted control.

$* p<0.05, * * p<0.0001$; Control vs G-CSF. 


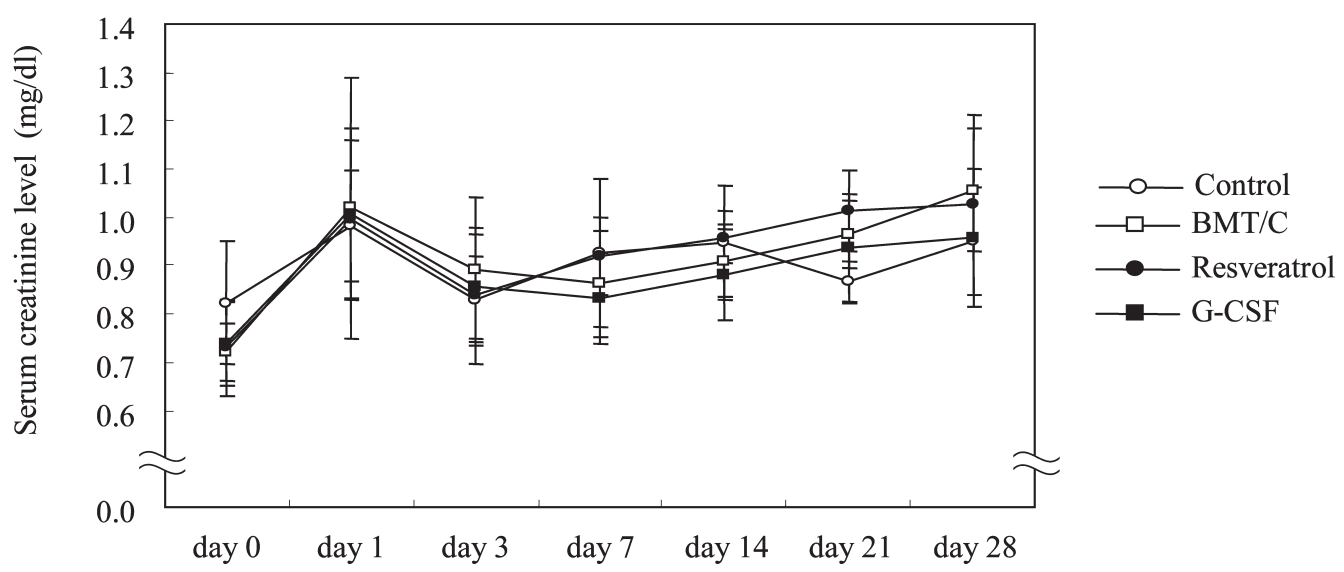

Fig. 3. Renal function after induction of renal ischemia/reperfusion injury. Serum creatinine levels, measured by Jaffe's method, peaked on day 1 in all groups. On day 28, the mean creatinine level of the G-CSF group $(0.96 \mathrm{mg} / \mathrm{dl})$ was not different from that of the control group $(0.95 \mathrm{mg} / \mathrm{dl}, p=0.92)$, BMT/C group $(1.06 \mathrm{mg} / \mathrm{dl}, p=0.13)$ and resveratrol group $(1.03 \mathrm{mg} / \mathrm{dl}, p=0.4)$. BMT/C, irradiated and bone-marrow-transplanted control.

\section{Serum creatinine level}

Serum creatinine levels reached a peak on day 1 in all groups. There was no significant difference in the peak creatinine level among all groups. On day 28, the mean creatinine level of the G-CSF group $(0.96 \mathrm{mg} / \mathrm{dl})$ was not different from that of the control group $(0.95 \mathrm{mg} / \mathrm{dl}, p=$ $0.92), \mathrm{BMT} / \mathrm{C}$ group $(1.06 \mathrm{mg} / \mathrm{dl}, p=0.13)$ and resveratrol group $(1.03 \mathrm{mg} / \mathrm{dl}, p=0.4)$ (Fig. 3).

\section{Y-chromosome-positive cells}

First, a chimerism in BMDC was analyzed in three mice 4 weeks after irradiation and bone marrow transplantation. All bone marrow cells obtained from the femuri of these mice were shown to have one Y-chromosome signal, and were confirmed to be of donor origin (data not shown).

Next, we evaluated the effect of G-CSF and resveratrol on the reconstruction of renal capillaries and tubuli. Factor VIII-related antigenpositive cells with a Y-chromosome signal were clearly identified on the luminal side of the capillary wall between renal tubuli (Fig. 4A). Most of these cells were observed in the boundary between the cortex and medulla, but some were also found in the medulla. The morphologic appearances of these cells were compatible with those of capillary endothelial cells. The mean number of those cells was $0.0 \pm 0.0,2.71 \pm 1.25$, $3.71 \pm 1.50$ and $10.2 \pm 1.33$ in the middle power field $(\times 400)$ in non-irradiated control, BMT/C, resveratrol and G-CSF groups, respectively, and was highest in the G-CSF group $(p<0.0001)$ (Fig. $5)$. Occasionally we found cellular nuclei positive for a Y chromosome in the renal tubuli, and careful microscopic observation revealed these nuclei to be infiltrated or superimposed nuclei of nontubular-epithelial cells. No cytokeratin18-positive renal tubular cells having a Y-chromosome signal were identified in any mice in this study (Fig. 4B).

\section{Discussion}

Similar to a study by Crosby et al. (2000) that showed hematopoietic stem cell transformation into adult blood vessels in the heart, we found that BMDC were mobilized to the kidney after I/R injury and transformed into endothelial cells. These endothelial cells were most frequently identified in the boundary between the cortex and medulla, where I/R injury has been shown to occur most severely (Kale et al. 2003). This finding suggests that BMDC are recruited to the injured area of the kidney and play a role in repairing the injury. Since we did not evaluate leucocyte markers on endothelial cells, our finding does not exclude possible fusion between 

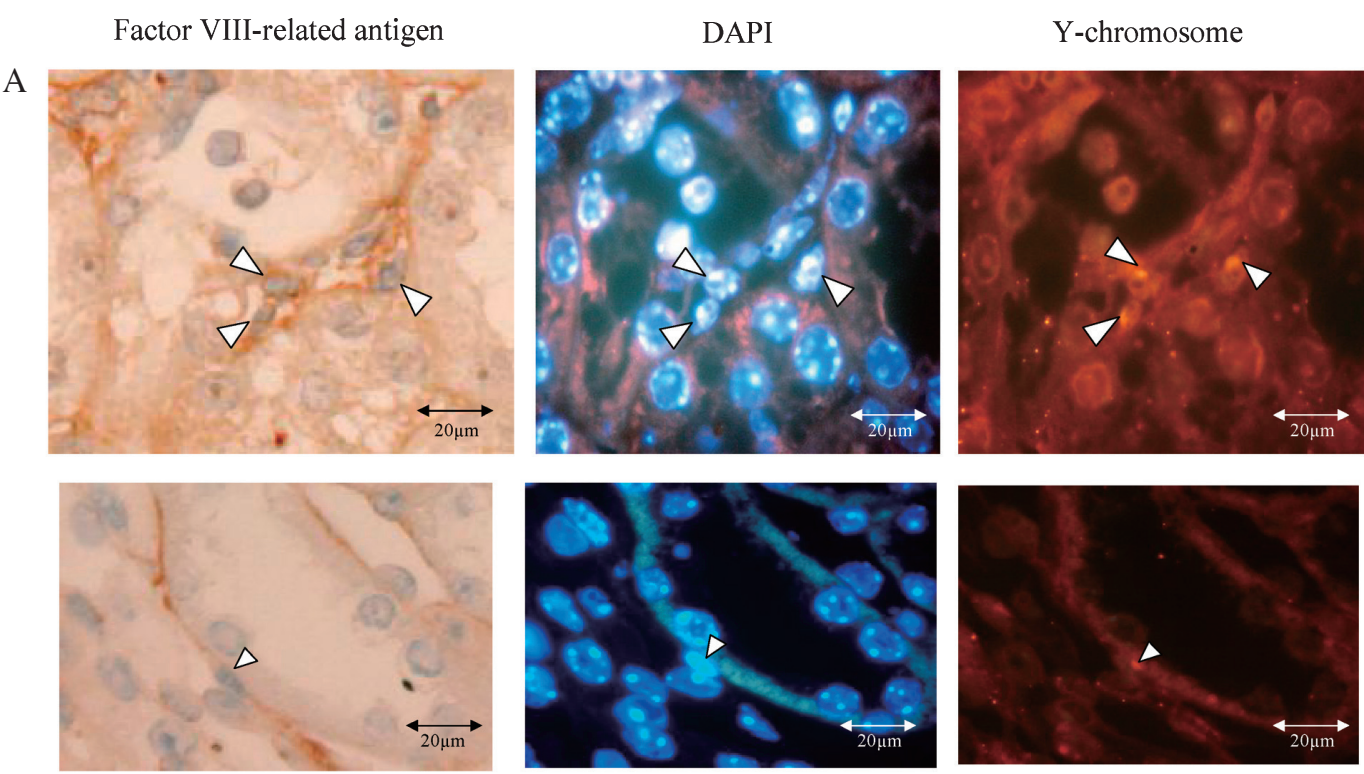

cytokeratin 18

B

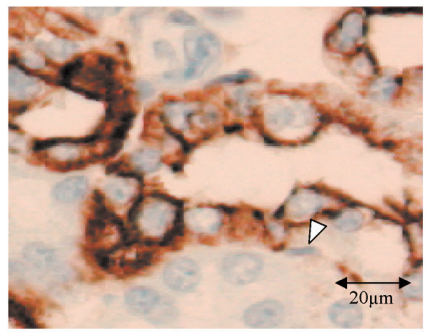

DAPI

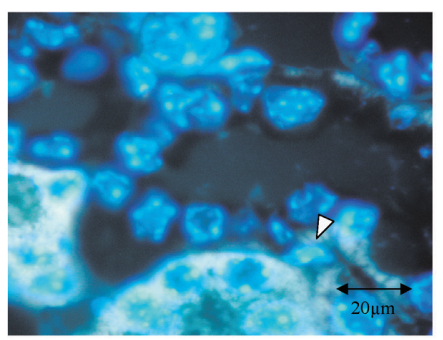

Y-chromosome

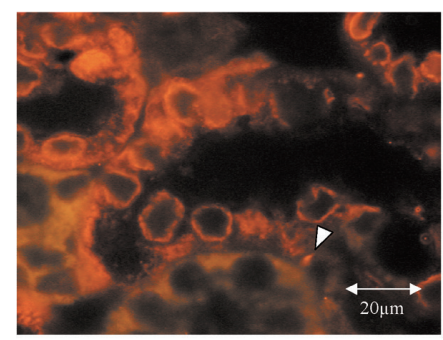

Fig. 4. Immunohistochemistry and fluorescence in situ hybridization of mouse kidneys 4 weeks after induction of renal ischemia/reperfusion injury. Factor VIII-related antigen-positive cells with a Y-chromosome signal were clearly identified in the capillary wall between renal tubuli (Fig. 4A). Arrows $(\nabla)$ indicate the same nuclei. Upper row: boundary between cortex and medulla. Lower row: medulla. Factor VIII-related antigen (original magnification $\times 200$ ), DAPI and Y-chromosome (magnification $\times 1,000)$.

However, no cytokeratin-positive renal tubular cell having a Y-chromosome signal was identified (Fig. 4B). Arrows $(\nabla)$ indicate the same nucleus of non-renal-tubular interstitial cells with a Y-chromosome but negative for cytokeratin 18. Cytokeratin 18, DAPI and Y-chromosome (magnification $\times 1,000)$. DAPI, 4,6-diamino-2-phenylindole $\mathrm{p}$-phenylenediamine

BMDC and endothelial cells as a mechanism of endothelial transformation, which has been suggested by Reinders et al. (2006). In a recent review, Young et al. (2007) suggested that endothelial progenitor cells, a fraction of BMDC, can proliferate and differentiate into endothelial cells in vitro. Further studies are required to elucidate whether these progenitor cells maintain proliferating ability in renal tissue damaged by $\mathrm{I} / \mathrm{R}$ injury.

In this study, G-CSF seemed to facilitate the transformation of BMDC into endothelial cells in the kidney after I/R injury. The number of endothelial cells judged to be transformed from BMDC by G-CSF was 3.7 or 2.7 times as high as that by saline administration or resveratrol, respectively. We did not count the number of BMDC in peripheral circulation that were mobilized from bone marrow by the administration of G-CSF. Classic BMDC are characterized by surface markers as Lin-Sca-1 + c-Kit + cells, and 
(/MPF)

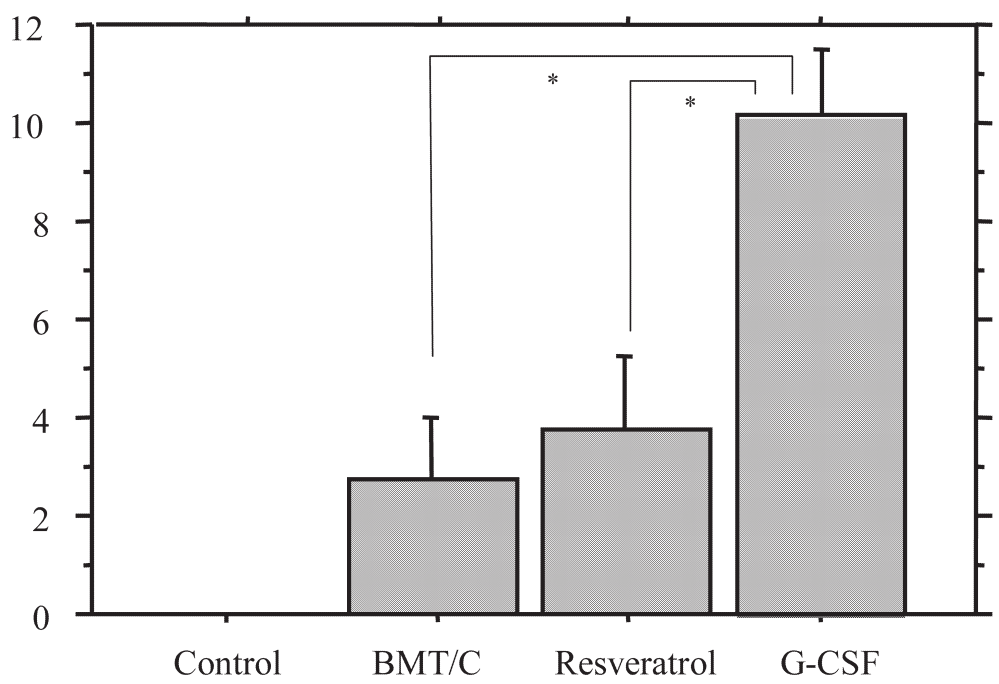

Fig. 5. Factor VIII-related antigen-positive cells with Y-chromosome signal in mouse kidneys 4 weeks after induction of renal ischemia/reperfusion injury. The mean number of those cells was $0.0 \pm 0.0$, $2.71 \pm 1.25,3.71 \pm 1.50$ and $10.2 \pm 1.33$ in the middle power field $(\times 400)$ in control, saline, resveratrol and G-CSF groups, respectively, and was highest in the G-CSF group $(p<0.0001)$. BMT/C, irradiated and bone-marrow-transplanted control.

$* p<0.0001, \mathrm{G}-\mathrm{CSF}$ vs BMT/C and G-CSF vs resveratrol.

these cells represent only $0.01 \%$ of BMDC that are not found in detectable numbers in the peripheral circulation under normal conditions (Kale et al. 2003). G-CSF and stem cell factor are suggested to mobilize BMDC at 250 times as high as the baseline level (Körbling and Estrov 2003). These BMDC contribute to the repopulation of the injured vascular endothelium and could indirectly affect renal tubular regeneration (Duffield et al. 2005; Reinders et al. 2006), and may facilitate early recovery from I/R renal injury.

Renal function recovery by G-CSF, however, was unremarkable in our study. Tögel et al. (2004) reported that BMDC mobilization via G-CSF had severe adverse effects on renal function after preconditioning with G-CSF; however, we gave G-CSF after inducing I/R injury, and no deterioration of renal function was found by G-CSF administration. The effect of G-CSF on the kidney during renal injury remains controversial and may, at least in part, depend on the time frame of C-CSF action (Nishida and Hamaoka 2006). Recent studies have elucidated the recovery mechanism after kidney injury (Rafii and Lyden
2003; Reinders et al. 2006; Young et al. 2007). Leucocytes and platelets in damaged renal tissue deliver angiogenesis factors, such as VEGF and SDF-1, into the local site. Endogenous G-CSF is also produced mainly by macrophages. These factors mediate the proliferation of local endothelial cells, and/or facilitate the recruitment of BMDC. If BMDC mobilized by the administration of G-CSF induces the majority repopulation of injured vascular endothelium, G-CSF might facilitate the recovery of renal function; however, our study was unable to find a substantial improving effect of G-CSF on the recovery of renal function as evaluated by the serum creatinine level. These endogenous angiogenesis factors may dominate exogenous G-CSF in capillary endothelial recovery in I/R injury, and thus G-CSF and BMDC made only a small contribution to repopulation of the injured vascular endothelium in our study model.

In our study, we failed to demonstrate renal tubular regeneration by BMDC. A review of recent studies which had claimed renal tubular regeneration by BMDC revealed that serum creat- 
inine post-I/R increased to 3.6 to 17.0 times as high as that of pre-I/R (Ysebaert et al. 2000; Brodsky et al. 2002; Duffield et al. 2005; Iwasaki et al. 2005). Broekema et al. (2005) reported that the severity of renal damage is associated with the extent of tubular epithelial regeneration by BMDC after I/R injury. Renal damage with a substantial but modest increase of serum creatinine in our study may thus have hampered the identification of tubular epithelial regeneration by BMDC. Recently, however, by deconvolution microscopic analysis, Duffield et al. (2005) suggested that tubular epithelial regeneration by BMDC was likely artifacts caused by the staining technique or the superimposition of a tubular cell and an infiltrating BMDC. Xenotransplantation of human hematopoietic stem cells into immunodeficient mouse kidneys after I/R injury demonstrated that these cells did not readily acquire a renal tubular cell phenotype and were restricted to hematopoietic lineage and, to a limited extent, endothelial lineages (Dekel et al. 2006). Thus, it remains to be clarified whether the cell source of tubular repair is the proliferation of endogenous renal cells or/and BMDC (Krause and Cantley 2005).

By investigating the restoration of endothelial cells and renal tubular cells, our study revealed that BMDC are recruited into endothelial cell in $\mathrm{I} / \mathrm{R}$ renal injury without apparent renal tubular cell regeneration. To our knowledge, this is the first report to demonstrate that endothelial cell regeneration occurs in mild $\mathrm{I} / \mathrm{R}$ renal injury in which renal tubular regeneration by BMDC has not taken place. In addition, this may fit the recent finding that endothelial damage preceded renal tubular damage in I/R injury and acute renal failure (Kakoki et al. 2000; Brodsky et al. 2002).

Resveratrol has been shown to restore kidney function in I/R injury in animal experiments (Giovannini et al. 2001; Saito et al. 2005), although our study on mice failed to demonstrate a protective effect. Giovannini et al. (2001) blocked rat renal arteries for 40 minutes and administered resveratrol at $0.23 \mu \mathrm{g} / \mathrm{kg}$, while Saito et al. (2005) blocked rat renal arteries for 60 min and administered resveratrol at $4 \mathrm{mg} / \mathrm{kg}$.
They both found decreased serum creatinine levels by resveratrol compared with the vehicle. These findings suggest that experimental conditions might explain the discrepancy between our findings and previous reports. Further studies are necessary to elucidate whether the resveratrol modifies the regenerating potential of BMDC by its tissue protective action.

In conclusion, our results confirm that BMDC are recruited into vascular endothelial cells of the kidney after I/R injury, while the regeneration of renal tubular cells originating from BMDC could not be demonstrated. Furthermore, the administration of G-CSF may facilitate the recruitment of bone marrow-derived endothelial cells while its contribution to kidney function recovery was not significant. In addition, resveratrol, an antioxidant, did not affect the recovery of kidney function in this model.

\section{References}

Brodsky, S.V., Yamamoto, T., Tada, T., Kim, B., Chen, J., Kajiya, F. \& Goligorsky, M.S. (2002) Endothelial dysfunction in ischemic acute renal failure: rescue by transplanted endothelial cells. Am. J. Physiol. Renal Physiol., 282, F1140-F1149.

Broekema, M., Harmsen, M.C., Koerts, J.A., Petersen, A.H., van Luyn, M.J., Navis, G. \& Popa, E.R. (2005) Determinants of tubular bone marrow-derived cell engraftment after renal ischemia/reperfusion in rats. Kidney Int., $\mathbf{6 8}$, 2572-2581.

Crosby, J.R., Kaminski, W.E., Schatteman, G., Martin, P.J., Raines, E.W., Seifert, R.A. \& Bowen-Pope, D.F. (2000) Endothelial cells of hematopoietic origin make a significant contribution to adult blood vessel formation. Circ. Res., 87, 728-730.

Dekel, B., Shezen, E., Even-Tov-Friedman, S., Katchman, H., Margalit, R., Nagler, A. \& Reisner, Y. (2006) Transplantation of human hematopoietic stem cells into ischemic and growing kidneys suggests a role in vasculogenesis but not tubulogenesis. Stem Cells, 24, 1185-1193.

Duffield, J.S., Park, K.M., Hsiao, L.L., Kelley, V.R., Scadden, D.T., Ichimura, T. \& Bonventre, J.V. (2005) Restoration of tubular epithelial cells during repair of the postischemic kidney occurs independently of bone marrow-derived stem cells. J. Clin. Invest., 115, 1743-1755.

Giovannini, L., Migliori, M., Longoni, B.M., Das, D.K., Bertelli, A.A., Panichi, V., Filippi, C. \& Bertelli, A. (2001) Resveratrol, a polyphenol found in wine, reduces ischemia reperfusion injury in rat kidneys. J. Cardiovasc. Pharmacol., 37, 262-270.

Iwasaki, M., Adachi, Y., Minamino, K., Suzuki, Y., Zhang, Y., Okigaki, M., Nakano, K., Koike, Y., Wang, J., Mukaide, H., Taketani, S., Mori, Y., Takahashi, H., Iwasaka, T. \& Ikehara, S. (2005) Mobilization of bone marrow cells by G-CSF rescues mice from cisplatin-induced renal failure, 
and M-CSF enhances the effects of G-CSF. J. Am. Soc. Nephrol., 16, 658-666.

Kakoki, M., Hirata, Y., Hayakawa, H., Suzuki, E., Nagata, D., Nishimatsu, H., Kimura, K., Goto, A. \& Omata, M. (2000) Effects of vasodilatory antihypertensive agents on endothelial dysfunction in rats with ischemic acute renal failure. Hypertens. Res., 23, 527-533.

Kale, S., Karihaloo, A., Clark, P.R., Kashgarian, M., Krause, D.S. \& Cantley, L.G. (2003) Bone marrow stem cells contribute to repair of the ischemically injured renal tubule. J. Clin. Invest., 112, 42-49.

Körbling, M. \& Estrov, Z. (2003) Adult stem cells for tissue repair - A new therapeutic concept? N. Engl. J. Med., 349, 570-582.

Krause, D. \& Cantley, L.G. (2005) Bone marrow plasticity revisited: protection or differentiation in the kidney tubule? J. Clin. Invest., 115, 1705-1708.

Lameire, N.H. \& Vanholder, R. (2004) Pathophysiology of ischaemic acute renal failure. Best Pract. Res. Clin. Anaesthesiol., 18, 21-36.

Lin, F., Cordes, K., Li, L., Hood, L., Couser, W.G., Shankland, S.J. \& Igarashi, P. (2003) Hematopoietic stem cells contribute to the regeneration of renal tubules after renal ischemia-reperfusion injury in mice. J. Am. Soc. Nephrol., 14, 1188-1199.

Masztalerz, M., Wlodarczyk, Z., Czuczejko, J., Slupski, M. \& Kedziora, J. (2006) Superoxide anion as a marker of ischemia-reperfusion injury of the transplanted kidney. Transplant. Proc., 38, 46-48.

Nishida, M. \& Hamaoka, K. (2006) How does G-CSF act on the kidney during acute tubular injury? Nephron. Exp. Nephrol., 104, e123-e128.

Orlic, D., Kajstura, J., Chimenti, S., Limana, F., Jakoniuk, I., Quaini, F., Nadal-Ginard, B., Bodine, D.M., Leri, A. \&
Anversa, P. (2001) Mobilized bone marrow cells repair the infarcted heart, improving function and survival. Proc. Natl. Acad. Sci. USA, 98, 10344-10349.

Rafii, S. \& Lyden, D. (2003) Therapeutic stem and progenitor cell transplantation for organ vascularization and regeneration. Nat. Med., 9, 702-712.

Reinders, M.E., Rabelink, T.J. \& Briscoe, D.M. (2006) Angiogenesis and endothelial cell repair in renal disease and allograft rejection. J. Am. Soc. Nephrol., 17, 932-942.

Saito, M., Satoh, S., Kojima, N., Tada, H., Sato, M., Suzuki, T., Senoo, H. \& Habuchi, T. (2005) Effects of a phenolic compound, resveratrol, on the renal function and costimulatory adhesion molecule CD86 expression in rat kidneys with ischemia/reperfusion injury. Arch. Histol. Cytol., 68, 41-49.

Takahashi, T., Kalka, C., Masuda, H., Chen, D., Silver, M., Kearney, M., Magner, M., Isner, J.M. \& Asahara, T. (1999) Ischemia- and cytokine-induced mobilization of bone marrow-derived endothelial progenitor cells for neovascularization. Nat. Med., 5, 434-438.

Tögel, F., Isaac, J. \& Westenfelder, C. (2004) Hematopoietic stem cell mobilization - Associated granulocytosis severely worsens acute renal failure. J. Am. Soc. Nephrol., 15, 1261-1267.

Young, P.P., Vaughan, D.E. \& Hatxopoulos, A.K. (2007) Biologic properties of endothelial progenitor cells and their potential for cell therapy. Prog. Cardiovasc. Dis., 49, 421-429.

Ysebaert, D.K., De Greef, K.E., Vercauteren, S.R., Ghielli, M., Verpooten, G.A., Eyskens, E.J. \& De Broe, M.E. (2000) Identification and kinetics of leukocytes after severe ischaemia/reperfusion renal injury. Nephrol. Dial. Transplant., 15, 1562-1574 